\title{
Choledochal cyst in infancy and childhood
}

\author{
Analysis of 16 cases
}

\author{
AKIO KOBAYASHI AND YOSHIRO OHBE \\ From the Section of Gastroenterology, Department of Paediatrics, National Children's Hospital, Tokyo
}

SUMMARY Choledochal cyst was diagnosed before operation in 14 out of 16 infants and children by means of a combination of diagnostic tests. Ultrasonic echogram showed a cystic mass in all 11 patients examined. The characteristic displacement of the duodenum was noted in 9 of 14 patients by contrast studies of the upper gastrointestinal tract, and hepatobiliary scintiscanning confirmed choledochal cyst in 7 of 8 patients $(88 \%)$. A cyst was shown by oral or intravenous cholangiography in 3 of 4 patients.

Onset of symptoms occurred from 7 days of age to 9.5 years; in 10 patients onset occurred under 12 months of age, in 3 from 13 to 24 months, and in the remaining 3 from 2 to $9 \cdot 5$ years. The first symptoms were jaundice, vomiting, acholic stools, and poor sucking. Obstructive jaundice and acholic stools were found in more than $80 \%$ of the patients, and abdominal mass in $60 \%$. Vomiting occurred in $50 \%$ of the patients, one-third of whom showed failure to thrive, and $70 \%$ of patients over the age of 1.5 years had abdominal pain. About half of the patients had a mild to moderate degree of fever.

In all patients primary excision of the cyst was followed by hepaticojejunostomy in Roux-en-Y fashion. The postoperative course was uneventful in 14 patients; 2 patients died, one from ascending cholangitis and one from hepatic failure.

Congenital cystic dilatation of the common bile duct, also known simply as choledochal cyst, is a rarely encountered condition, which until recently was usually not diagnosed before surgery. Many paediatricians are unfamiliar with the disorder because of its rarity and variable clinical manifestations (Mahour, 1973). However, most patients in the paediatric age range will be first seen at paediatric clinics, and paediatricians should keep in mind the clinical features and methods of diagnosing the disease. Since few reports have appeared in paediatric journals, we describe here the clinical features of 16 patients and discuss the usefulness of several investigations.

\section{Case reports}

Between January 1967 and December 1975, a total of 16 patients ( 13 females, 3 males) with choledochal cyst were admitted to this hospital. Ages on admission ranged from 1.5 months to 9.5 years. They all had laparotomy and diagnosis was confirmed by operative cholangiography.

Received 7 May 1976.
Case 1. A female aged 1.5 months was admitted with poor sucking and vomiting since the first week of life. She was mildly jaundiced and had transient clay-coloured stools, but looked well nourished. Weight was $3900 \mathrm{~g}$ and height $53 \mathrm{~cm}$. The abdomen was moderately distended and the liver palpable 2 finger-breadths below the costal margin. An abdominal mass was found in the right upper quadrant.

Laboratory studies on admission showed only slightly raised serum bilirubin. Roentgenological studies of the upper gastrointestinal tract (Fig. 1) and an ultrasonic echogram confirmed a choledochal cyst. At the age of 3 months she was treated by excision of the cyst followed by hepaticojejunostomy in Roux-en-Y fashion. Operative cholangiography showed a large cyst (Fig. 2). The postoperative course was uneventful.

Case 3. A female aged 7 months was admitted with jaundice from birth. Stools were at times claycoloured. From the age of one month she was treated as having neonatal hepatitis with no essential improvement. Physical examination showed a well nourished infant weighing $7350 \mathrm{~g}$, height $61 \mathrm{~cm}$, with obstructive aundice, marked abdominal 


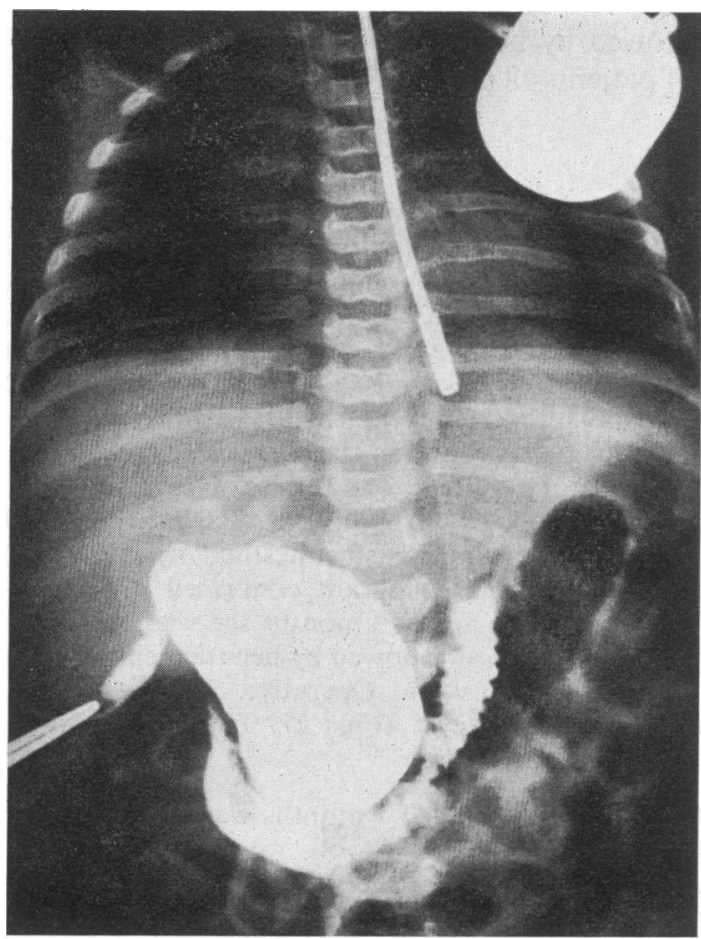

Fig. 2 Case 1. Cyst shown by operative cholangiography. distension, and hepatomegaly (3 finger-breadths below the costal margin).

Conspicuously high serum bilirubin and serum alkaline phosphatase were the only biochemical abnormalities. Barium meal showed a markedly displaced duodenum anteriorly and inferiorly (Fig. 3a, b). After diagnosis of a choledochal cyst, a primary excision was made and hepaticojejunostomy in Roux-en-Y fashion were done at the age of 7 months. 2 months after surgery she developed ascites due to cirrhosis and died.

Case 7. A female was admitted with jaundice and clay-coloured stools at 11 months of age. She had been in good health until the age of 6 months when she developed mild jaundice and acholic stools. Diarrhoea and vomiting occurred at the same time and persisted for 5 weeks. 4 months later mild jaundice reappeared with pruritus. She was then referred to us. Physical examination showed a well nourished infant in no distress, weighing $9400 \mathrm{~g}$, height $74 \mathrm{~cm}$. She had mild jaundice, marked abdominal distension, hepatomegaly, and an abdominal mass beneath the liver. There were no other abnormal findings.

Serum alkaline phosphatase was high and serum cholesterol slightly raised, as was serum bilirubin. There were no other abnormalities. Ultrasonic echogram indicated the presence of a cyst (Fig. 4) and a barium study of the upper gastrointestinal 


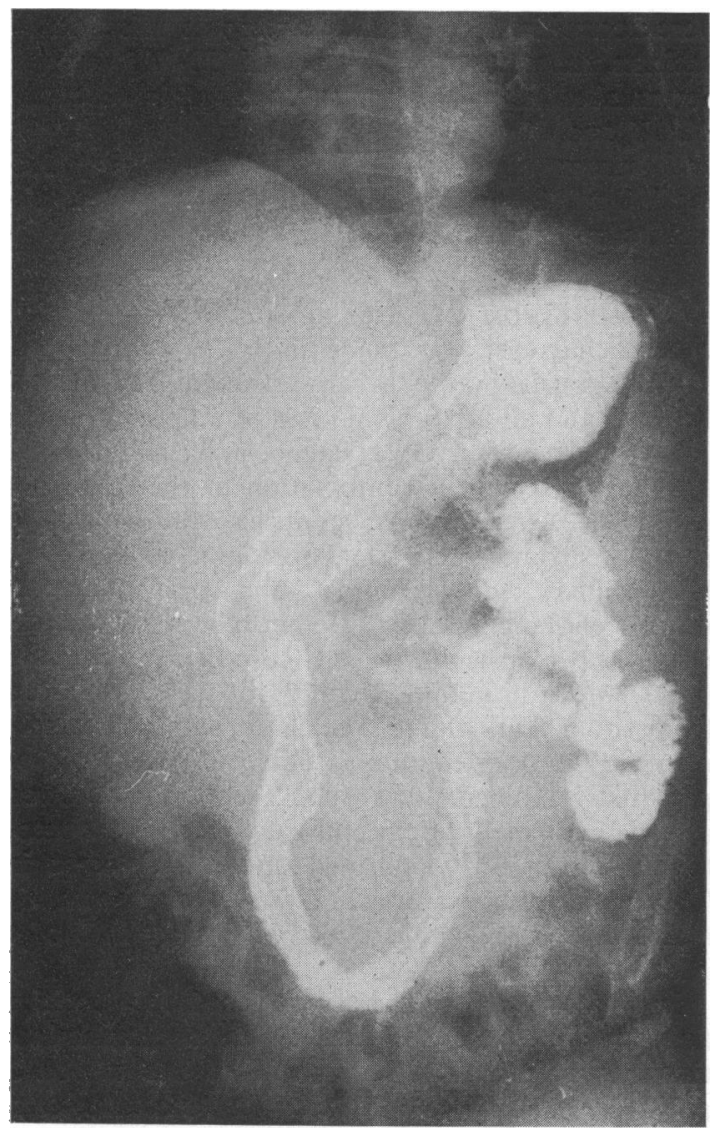

(a)

tract showed anterior and inferior displacement of the duodenum. Hepatobiliary scintiscanning showed a choledochal cyst (Fig. 5a, b). At laparotomy a large, tense choledochal cyst, $14 \mathrm{~cm}$ in diameter, was seen. After excision of the cyst, hepaticojejunostomy in Roux-en-Y fashion was carried out. Thereafter the clinical course was uneventful.

\section{Results}

Clinical features (Table 1). Onset of symptoms in the 16 patients was from 7 days to $9 \cdot 5$ years of age; in two-thirds onset occurred under 12 months. The initial symptoms were jaundice in half of the patients, vomiting in one-third, and acholic stools in one-fifth, abdominal pain in 2 patients, abdominal distension in 2 , and poor sucking in one. The chief complaints on admission were jaundice in 14 patients $(88 \%)$, vomiting $2(13 \%)$, abdominal distension 2 , acholic stools 2, abdominal pain 2, and poor sucking in 2 .

Fourteen of the 16 patients $(88 \%)$ had been

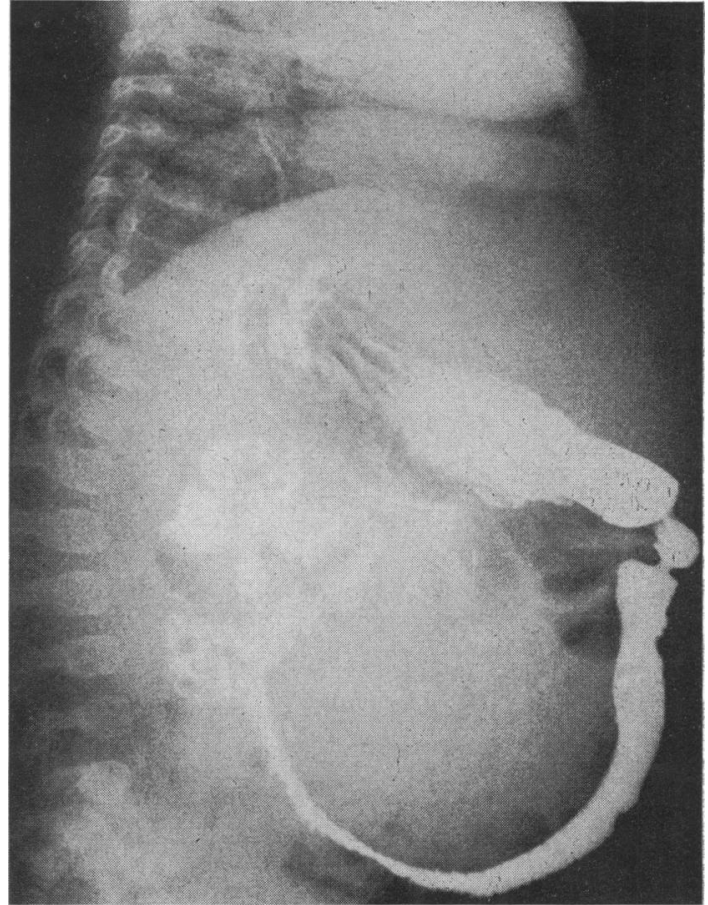

(b)

Fig. 3 Case 3. Barium meal showed marked anterior and inferior displacement of duodenum. (a) Anteroposterior view; (b) lateral view.

jaundiced at some time before diagnosis was established, though the degree of jaundice was variable in each case. Abdominal pain was noted in 5 out of 7

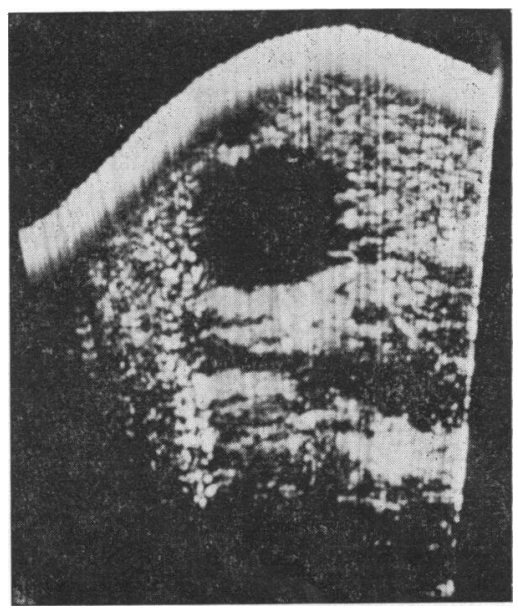

Fig. 4. Case 7. Ultrasonic echography showing a cystic mass. 


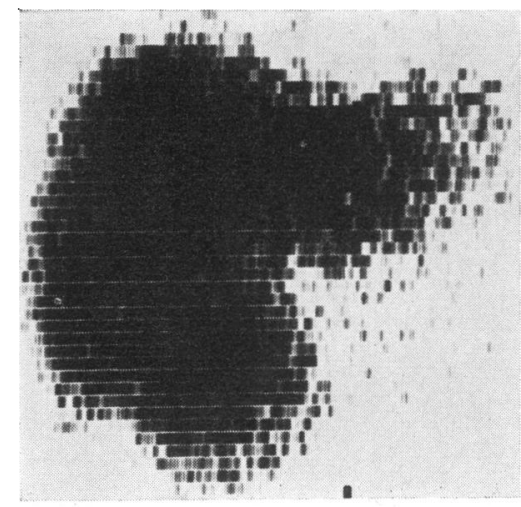

(a)

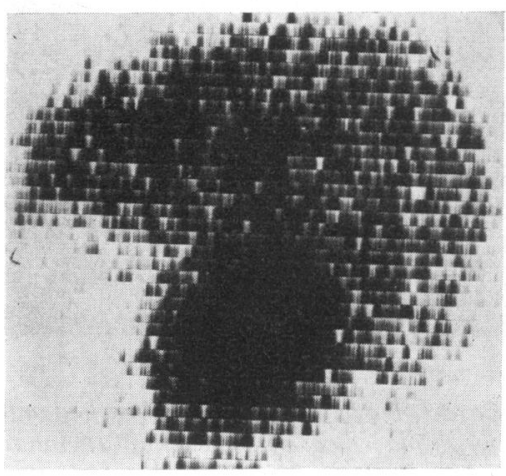

(b)

Fig. 5 Case 7. Hepatobiliary scintiscanning 3 hours after injection of $140 \mu C i^{131}$ I-Rose Bengal, showing a choledochal cyst. (a) Anteroposterior view;

(b) lateral view.

patients over one year of age, and vomiting in half of the patients. Vomiting and poor sucking were noted in the newborns and infants more often than in the older children. In 3 infants vomiting and failure to thrive were prominent features. 14 patients $(88 \%)$ had acholic stools at some time before surgery. 3 of these 14 had acholic stools as consistently as those with biliary atresia. A moderate degree of fever was observed in 7 patients $(44 \%)$. An abdominal mass was found in 10 of the 16 patients (63\%), hepatomegaly was noted in $7(44 \%)$, and 1 infant had pruritus.

Laboratory findings (Table 2). Erythrocyte sedimentation rate was moderately raised in twothirds of the patients examined. Only one patient had anaemia (haemoglobin $<10 \mathrm{~g} / \mathrm{dl}$ ). Moderate leucocytosis was noted in nearly half of the patients. Thymol turbidity test and zinc sulphate turbidity were normal in all. Serum bilirubin was raised in 14 patients, range $2 \cdot 9-14 \cdot 3 \mathrm{mg} / 100 \mathrm{ml}(50-245 \mu \mathrm{mol} / \mathrm{l})$. Serum alkaline phosphatase was raised in all cases, SGOT and SGPT were slightly raised in nearly all, and serum cholesterol was high, reaching 925 $\mathrm{mg} / 100 \mathrm{ml}(24 \mathrm{mmol} / \mathrm{l})$ in Case 15 . Plasma protein and its fractions were nearly normal.

Diagnosis (Table 2). A preoperative diagnosis of choledochal cyst was made in 14 of 16 patients. The diagnosis in the other 2 was biliary atresia (Case 6) and an abdominal mass of unknown origin (Case 15), respectively. Diagnosis of choledochal cyst was based on a combination of the following diagnostic examinations: contrast studies of the upper gastrointestinal tract, ultrasonic echography, hepatobiliary scintiscanning, and oral or intravenous cholangiography. Hepatobiliary scintiscanning was performed using ${ }^{131}$ I-Rose Bengal in a dose of $60-80 \mu \mathrm{Ci}$ in infants and $120-160 \mu \mathrm{Ci}$ in children from 1 to 6 years of age. The characteristic displacement of the duodenum was noted in two-thirds of patients examined. Ultrasonic echogram showed a cystic mass in all 11 patients examined and hepatobiliary scintigram confirmed choledochal cyst in 7 of 8 patients examined. Cysts were shown by oral and/or intravenous cholangiography in 3 of 4 patients.

In 4 patients the diagnosis was based on a positive finding in any one of the above-mentioned examinations. In 5 patients the diagnosis was based on 2 positive tests, and in 4 patients on 3 positive tests. All four tests were positive in only one patient.

Pathology. At operation, the size of the cyst varied, the largest being $17 \mathrm{~cm}$ in diameter. According to the classification of Alonso-Lej et al. (1959), these 16 patients belonged to type 1, i.e. generalized enlargement of a segment of the bile duct in continuity. The intrahepatic bile ducts were dilated in 2 cases (Cases 6, 14) (Fig. 6), in one of which gallstones were found in the dilated ducts. The other (Case 6) developed ascending cholangitis and died.

Treatment and outcome (Table 1). All patients were treated by primary excision of the choledochal cyst followed by hepaticojejunostomy in Roux-en-Y fashion. Their ages at operation ranged from 2 months to 9.5 years. Though the postoperative course was uneventful in 14 patients and they have been well from 2 months to 7 years after operation; 2 died, one from hepatic failure (Case 3 ) and the other (Case 6) from ascending cholangitis 2 and 12 months after surgery. 


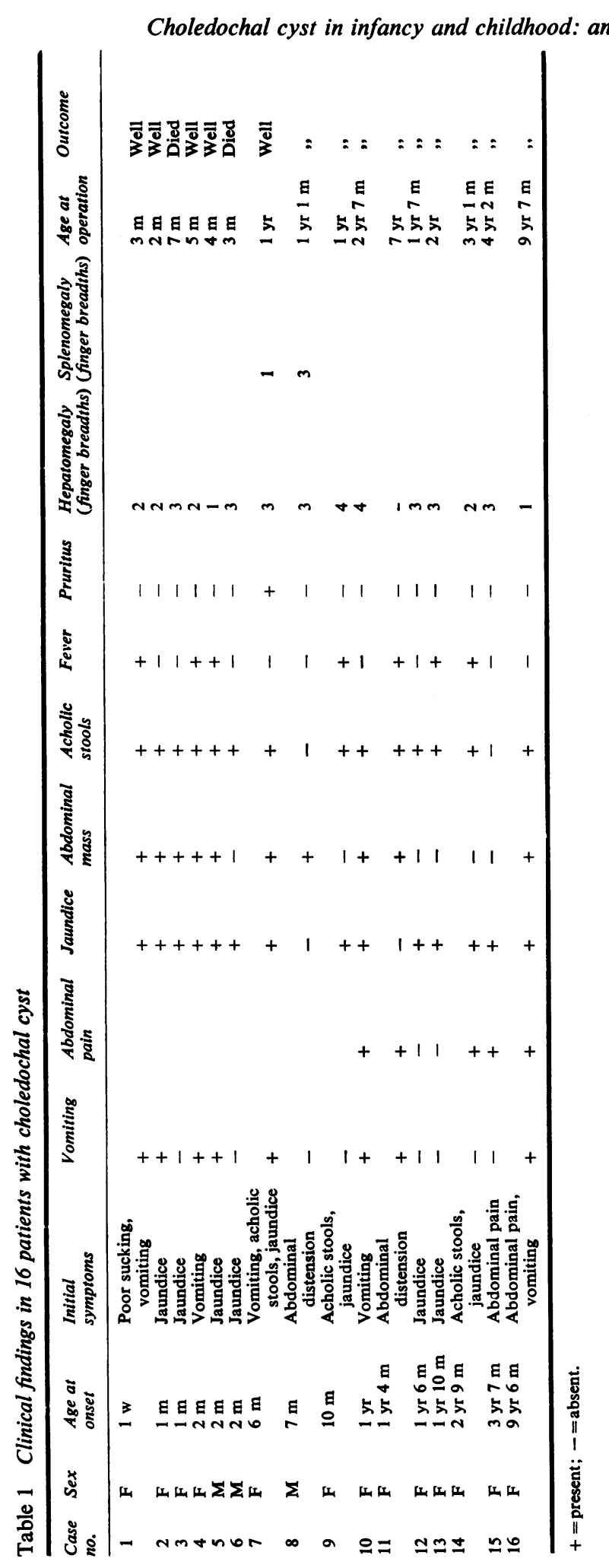


Table 2 Laboratory findings in 16 patients with choledochal cyst

\begin{tabular}{|c|c|c|c|c|c|c|c|c|c|}
\hline $\begin{array}{l}\text { Case } \\
\text { no. }\end{array}$ & $\begin{array}{l}E S R \\
(m m / h)\end{array}$ & $\begin{array}{l}\text { Haemoglobin } \\
(\mathrm{g} / \mathrm{dl})\end{array}$ & $\begin{array}{l}W B C \\
\left(/ m^{3}\right)\end{array}$ & $\begin{array}{l}T T T \\
\text { (units) }\end{array}$ & $\begin{array}{l}Z n S \\
\text { (units) }\end{array}$ & $\begin{array}{l}\text { Total } \\
\text { bilirubin } \\
\text { (direct) } \\
(\mathrm{mg} / 100 \mathrm{ml})\end{array}$ & $\begin{array}{l}\text { Alkaline } \\
\text { phosphatase } \\
\text { (K-K units) }\end{array}$ & $\begin{array}{l}\text { SGOT } \\
\text { (units) }\end{array}$ & $\begin{array}{l}\text { SGPT } \\
\text { (units) }\end{array}$ \\
\hline $\begin{array}{l}1 \\
2 \\
3 \\
4 \\
5 \\
6 \\
7 \\
8 \\
9 \\
10 \\
11 \\
12 \\
13 \\
14 \\
15 \\
16\end{array}$ & $\begin{array}{r}63 \\
13 \\
26 \\
31 \\
49 \\
\\
13 \\
34 \\
9 \\
66 \\
28\end{array}$ & $\begin{array}{r}10 \cdot 1 \\
12 \cdot 3 \\
11 \cdot 3 \\
10 \cdot 6 \\
9 \cdot 2 \\
12 \cdot 4 \\
10 \cdot 0 \\
11 \cdot 4 \\
11 \cdot 6 \\
17 \cdot 8 \\
16 \cdot 1 \\
13 \cdot 6 \\
12 \cdot 0 \\
15 \cdot 0 \\
12 \cdot 6 \\
14 \cdot 2\end{array}$ & $\begin{array}{r}16600 \\
12200 \\
8600 \\
9800 \\
10300 \\
8000 \\
13100 \\
9500 \\
20400 \\
19900 \\
9600 \\
10400 \\
12600 \\
9500 \\
15300 \\
4400\end{array}$ & $\begin{array}{l}3 \cdot 6 \\
0.6 \\
1 \cdot 1 \\
3 \cdot 1 \\
3 \cdot 3 \\
2 \cdot 9 \\
6 \cdot 4 \\
2 \cdot 1 \\
0 \cdot 8 \\
2 \cdot 2 \\
1 \cdot 8 \\
2 \cdot 4 \\
3.4 \\
1 \cdot 8\end{array}$ & $\begin{array}{l}3 \cdot 5 \\
1 \cdot 9 \\
2 \cdot 0 \\
3 \cdot 5 \\
1 \cdot 0 \\
3 \cdot 7 \\
3 \cdot 5 \\
2 \cdot 1 \\
6 \cdot 9 \\
1 \cdot 8 \\
2 \cdot 9 \\
2 \cdot 0 \\
1 \cdot 4 \\
1 \cdot 7 \\
1 \cdot 7 \\
2 \cdot 6\end{array}$ & 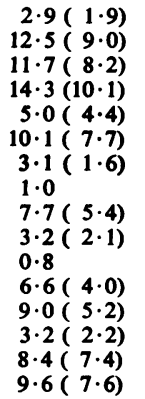 & $\begin{array}{c}21 \cdot 4 \\
23 \cdot 0 \\
135 \\
99 \\
\\
131 \\
170 \\
120 \\
160 \\
60 \\
23 \cdot 6 \\
75 \\
18 \cdot 8 \\
126 \\
119 \\
53\end{array}$ & $\begin{array}{r}29 \\
132 \\
125 \\
170 \\
32 \\
200 \\
83 \\
53 \\
146 \\
153 \\
12 \\
134 \\
141 \\
104 \\
198 \\
163\end{array}$ & $\begin{array}{r}26 \\
95 \\
35 \\
73 \\
15 \\
120 \\
76 \\
25 \\
123 \\
168 \\
30 \\
160 \\
95 \\
70 \\
153 \\
145\end{array}$ \\
\hline
\end{tabular}

$\mathrm{ESR}=$ erythrocyte sedimentation rate; $\mathrm{TTT}=$ thymol turbidity test $\mathbf{Z n S}=$ zinc sulphate.

Conversion: Traditional units to SI-White blood count: $1000 / \mathrm{mm}^{3} \approx 1 \cdot 0 \times 10^{9} / 1$. Bilirubin: $1 \mathrm{mg} / 100 \mathrm{ml} \approx 17 \cdot 1 \mu \mathrm{mol} / 1$. Cholesterol: $1 \mathrm{mg} / 100 \mathrm{ml} \approx$

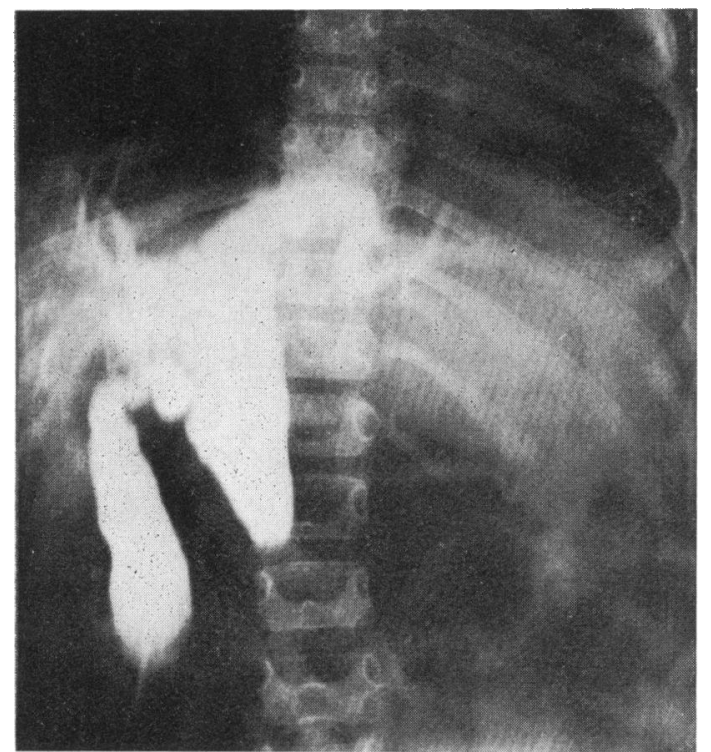

Fig. 6 Case 14. Operative cholangiography showed dilatation of both the extra-and intrahepatic bile ducts.

\section{Discussion}

The cause of choledochal cyst is unknown and several hypotheses have been presented as to the aetiology. The condition is generally considered to be congenital in origin. Alonso-Lej et al. (1959) classified the disorder into three types: (1) generalized enlargement of a segment of the common duct in continuity, (2) a diverticulum of a normal or slightly dilated common duct, and (3) a choledochocele, restricted to the intraduodenal portion of the common duct. The latter two are extremely rare. In our series all patients belonged to type 1. Dilatation of the intrahepatic bile ducts was found in 2 of 16 patients. Tsuchida and Ishida (1971) reported that the malformation was more frequent than expected (Gots and Zuidema, 1970), and was seen in 9 of 16 cases by operative choangiography.

The disease is more common in females (Lee et al., 1969), and in the present series 13 of the 16 patients $(81 \%)$ were female. The incidence is approximately four times higher in Japan than in Europe or America (Lee et al., 1969). Although choledochal cyst is a rare condition, its clinical features have been delineated as more cases have been reported. Obstructive jaundice and acholic stools were found in more than $80 \%$ of the patients, and abdominal mass was noted in $60 \%$. It was difficult to know whether young children and infants had abdominal pain. In the present series the pain was present in $70 \%$. Vomiting occurred in $50 \%$ of the cases, one-third of whom exhibited failure to thrive. Nearly half of the patients had a mild to moderate degree of fever. The classic triad of abdominal pain, jaundice, and abdominal mass was present in only 2 patients $(13 \%), 2$ of the triad were present in $9(56 \%)$, and one in $5(31 \%)$. The classical triad was, therefore, of little value for diagnosis of choledochal cyst.

When some of the symptoms are present and choledochal cyst is suspected, the following diagnostic procedures are necessary to confirm the diagnosis, in this order: ultrasonic echography, roentgenological studies of the upper gastrointestinal tract, and hepatobiliary scintiscanning. Oral 


\begin{tabular}{|c|c|c|c|c|c|c|}
\hline $\begin{array}{l}\text { Lactic } \\
\text { dehydrogenase } \\
\text { (units) }\end{array}$ & $\begin{array}{l}\text { Cholesterol } \\
(\mathrm{mg} / 100 \mathrm{ml})\end{array}$ & $\begin{array}{l}\text { Albumin/globulin } \\
(\mathrm{g} / \mathrm{l})\end{array}$ & $\begin{array}{l}\text { Ultrasonic } \\
\text { echography }\end{array}$ & $\begin{array}{l}\text { Contrast study } \\
\text { of duodenum }\end{array}$ & $\begin{array}{l}\text { Hepatobiliary } \\
\text { scintiscanning }\end{array}$ & $\begin{array}{l}\text { Oral and/or IV } \\
\text { cholangiography }\end{array}$ \\
\hline $\begin{array}{l}650 \\
434 \\
325 \\
450 \\
420 \\
400 \\
675 \\
420 \\
356\end{array}$ & $\begin{array}{l}212 \\
205 \\
186 \\
165 \\
305 \\
193 \\
572 \\
289 \\
147 \\
321 \\
455 \\
285 \\
925 \\
202\end{array}$ & $\begin{array}{l}41 / 20 \\
43 / 25 \\
34 / 34 \\
46 / 22 \\
38 / 26 \\
40 / 22 \\
45 / 33 \\
35 / 32 \\
47 / 36 \\
42 / 40 \\
44 / 42 \\
49 / 37 \\
41 / 33 \\
42 / 39 \\
45 / 34\end{array}$ & $\begin{array}{l}+ \\
+ \\
+ \\
+ \\
+ \\
+ \\
+ \\
+ \\
+\end{array}$ & $\begin{array}{l}+ \\
+ \\
+ \\
- \\
- \\
+ \\
+ \\
+ \\
+ \\
- \\
+ \\
+\end{array}$ & $\begin{array}{l}+ \\
+ \\
+ \\
+ \\
+ \\
+ \\
+\end{array}$ & $\frac{+}{+}$ \\
\hline
\end{tabular}

or intravenous cholangiography may occasionally be informative. In the present series, ultrasonic echography showed findings consistent with choledochal cyst in all patients examined. Since it is easy and safe to perform and produces no discomfort to the patients, it should be carried out first. This was used, however, as a screening test for choledochal cyst; a conclusive examination is needed for a definitive diagnosis.

The second procedure for diagnosis is contrast studies of the upper gastrointestinal tract and/or hepatobiliary scintiscanning. The latter was of more value than the roentgenological studies since it was informative in 6 of 7 patients, whereas widening of the duodenal C-loop was found in 9 of 12 patients. A combination of these procedures will determine the correct preoperative diagnosis. Visualization of a cyst by oral or intavenous cholangiography is usually impossible when biliary obstruction is so severe as to cause acholic stools. Oral or intravenous cholangiography is therefore the last diagnostic procedure to perform, though it is helpful in older children without significant jaundice.

Diseases which should be differentiated from choledochal cyst are duplication of the duodenum, mesenteric cyst, hepatic cyst, hydronephrosis, etc. These are easily ruled out by the combination of the diagnostic tests.

Internal drainage of the cyst into the intestinal tract has been considered appropriate, and choledochocystoduodenostomy (Fonkalsrud and Boles, 1965; Kirtley and Holcomb, 1966; Duckett et al., 1971) and choledochocystojejunostomy (Warren et al., 1968; Hays et al., 1969; Mahour and Lynn, 1969) have been widely used. Excision of the cyst and anastomosis of the remaining biliary tree to the intestinal tract has been advocated as the treatment of choice by several authors (Ishida et al., 1970; Kasai et al., 1970; Jones et al., 1971). In our series, primary excision of the cyst followed by hepaticojejunostomy was done in all 16 patients. The postoperative course was uneventful in 14 of 16 patients.

\section{References}

Alonso-Lej, F., Rever, W. B., Jr., and Pessagno, D. J. (1959). Congenital choledochal cyst, with a report of two, and an analysis of 94 cases. Surgery, Gynecology and Obstetrics. International Abstracts of Surgery, 108, 1-30.

Duckett, J., Eraklis, A. J., and Longino, L. (1971). Surgical treatment of idiopathic dilatation of the common bile duct (choledochal cyst) in 14 children. Journal of Pediatric Surgery, 6, 421-426.

Fonkalsrud, E. W., and Boles, E. T., Jr. (1965). Choledochal cysts in infancy and childhood. Surgery, Gynecology and Obstetrics, 121, 733-742.

Gots, R. E., and Zuidema, G. D. (1970). Dilatation of the intrahepatic biliary ducts in a patient with a choledochal cyst. American Journal of Surgery, 119, 726-728.

Hays, D. M., Goodman, G. N., Snyder, W. H., Jr., and Woolley, M. M. (1969). Congenital cystic dilatation of the common bile duct. Archives of Surgery, 98, 457-461.

Ishida, M., Tsuchida, Y., Saito, S., and Hori, T. (1970). Primary excision of choledochal cysts. Surgery, 68, 884888.

Jones, P. G., Smith, E. D., Clarke, A. M., and Kent, M. (1971). Choledochal cysts: experience with radical excision. Journal of Pediatric Surgery, 6, 112-120.

Kasai, M., Asakura, Y., and Taira, Y. (1970). Surgical treatment of choledochal cyst. Annals of Surgery, 172, 844-851.

Kirtley, J. A., Jr., and Holcomb, G. W., Jr. (1966). Surgical management of diseases of the gallbladder and common duct in children and adolescents. American Journal of Surgery, 111, 39-46.

Lee, S. S., Min, P. C., Kim, G. S., and Hong, P. W. (1969). Choledochal cyst. A report of nine cases and review of the literature. Archives of Surgery, 99, 19-28. 
Mahour, G. H. (1973). Choledochal cyst in infants. American Journal of Diseases of Children, 126, 533-534.

Mahour, G. H., and Lynn, H. B. (1969). Choledochal cyst in children. Surgery, 65, 967-971.

Tsuchida, Y., and Ishida, M. (1971). Dilatation of the intrahepatic bile ducts in congenital cystic dilatation of the common bile duct. Surgery, 69, 776-781.
Warren, K. W., Kune, G. A., and Hardy, K. J. (1968). Biliary duct cysts. Surgical Clinics of North America, 48, 567-577.

Correspondence to Dr. A. Kobayashi, Department of Paediatrics, National Children's Hospital, Taishido 3-35-31, Setagaya-ku, 154 Tokyo, Japan. 